\section{Azithromycin and Full-Mouth Scaling For the Treatment of Generalized Stage III and IV Periodontitis: A 6-Month Randomized Comparative Clinical Trial}

\author{
Alcione M. S. D. Oliveira ${ }^{\mathbb{D}}$, Fernando 0. Costa ${ }^{\mathbb{D}}$, Letícia Mara R. \\ Nogueira$^{3}{ }^{-}$, Sheila C. Cortelli ${ }^{\mathbb{D}}$, Peterson A. D. Oliveira ${ }^{4} \mathbb{D}^{\circ}$, Davi R.

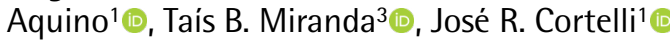

\begin{abstract}
The effectiveness of azithromycin combined with full-mouth scaling procedures was compared to quadrant-wise scaling combined with the same dosage of azithromycin when treating periodontitis patients over a 6-month period. In this randomized clinical trial study, thirty-four individuals diagnosed with generalized stage III and IV periodontitis underwent baseline, 3-month, and 6-month post-treatment examinations. The study population was randomly assigned to either full-mouth scaling (FMS) or quadrant-wise scaling and root planning (QSRP) in addition to their taking of systemic azithromycin (500 $\mathrm{mg} /$ day) for three consecutive days. Periodontal probing depth (PD), clinical attachment level (CAL), gingival index (GI), and plaque index (PI) were monitored along with the quantification of total bacterial load and red complex bacterial species (Porphyromonas gingivalis, Tannerella forsythia, and Treponema denticola) in subgingival samples by real time polymerase chain reaction. The volume of gingival crevicular fluid (GCF) was also monitored over time. The primary outcomes included improvements of PD and CAL. Data was statistically analyzed through a repeated-measures analysis of variance (ANOVA) test, multiple least significant difference (LSD) comparisons, Kruskal-Wallis, Friedman, and paired Student t-tests $(\mathrm{p}<0.05)$. FMS and QSRP provided similar PD, CAL, GI, PI, and GCF improvements. After treatment, the FMS group displayed lower mean values of total bacterial load and red complex bacterial species in comparison to the QSRP group. FMS and QSRP in conjunction with systemic azithromycin appeared to be an effective and reliable short-term therapeutic approach for the treatment of generalized stage III and IV periodontitis. However, FMD demonstrated superiority in regard to the 6-month antibacterial effects when compared to QSRP.
\end{abstract}

'Nucleus of Periodontal Tesearch, Dental School, UNITAU - Universidade de Taubaté, Taubaté, SP, Brazil 2Periodontal Department, Dental School, UFMG - Universidade Federal de Minas Gerais, MG, Belo Horizonte, Brazil ${ }^{3}$ Dental School, UNITAU Universidade de Taubaté, Taubaté, SP, Brazil ${ }^{4}$ Periodontal Department, Dental School, PUC - Pontifícia Universidade Católica de Minas Gerais, Belo Horizonte, MG, Brazil

Correspondence: Alcione Maria Soares Dutra Oliveira, Avenida Dom José Gaspar, 500, 30535901 Belo Horizonte, MG, Brasil. Tel: +55-31-3319-4409. e-mail: alcionemsdo@gmail.com

Key Words: periodontitis, azithromycin, dental scaling, therapeutics.

\section{Introduction}

Periodontitis is a mixed infection primarily caused by periodontal pathogens existing within subgingival plaque. Diverse bacteria exist in the subgingival plaque, forming an extremely complicated bacterial flora. Additionally, periodontitis is characterized by the progressive destruction of the tissues supporting the teeth (1).

Commensal bacterial species are key microorganisms in regard to oral homeostasis. When a decrease in the levels of advantageous symbionts occurs with a simultaneous increase of pathogenic bacteria, normal periodontal tissue function is disturbed, allowing disease to spread (2). Therefore, periodontitis is a dysbiotic disease resulting from the broken symbiotic relationship between host and microbe (3). Key pathogenic species, such as Porphyromonas gingivalis, Tannerella forsythia, and Treponema denticola, are capable of disrupting periodontal homeostasis (4-6).

The conventional treatment for periodontal diseases is quadrant-wise scaling and root planning (OSRP), otherwise known as non-surgical periodontal therapy. This is the process of removing local etiologic agents, including dental biofilm and its products and supra- and subgingival dental calculus. The standard treatment is performed in four weekly sections, with one or two quadrants treated per dental visit. The study by Badersten et al. (7), which employed manual instruments, found that the effectiveness of calculus removal is influenced by initial pocket depth, tooth type and surface, and operator experience.

Although the quadrant-wise treatment has been the conventional option in the past, the full-mouth disinfection (FMD) emerged as an alternative that avoids the transmission of pathogenic microorganisms from untreated periodontal pockets to those recently debrided, thus healing in the process. The protocol proposed by Quirynen et al. (8), called "one-stage full-mouth disinfection," includes one-stage $(24 \mathrm{~h})$ scaling and root planning procedures divided into two sessions (60 min per session) performed within two consecutive days and features the combination of chlorhexidine ( $\mathrm{CHX}$ ) subgingival irrigation and daily $\mathrm{CHX}$ mouth washing for two weeks. Benefits of this protocol included the potential stimulus of the immunological response and an improved cost-benefit relation (9). 
Both types of treatment (i.e., OSRP and full-mouth scaling FMS) can be associated with systemic antimicrobials, which display additional benefits in comparison to mechanical procedures alone. In general, authors have not supported the superiority of one of these protocols over the other (10-12). However, some authors, such as Fang et al. (13), prefer to recommend FMS due to its minimal additional clinical benefits. Among the available systemic antimicrobials, azithromycin has been used as an adjuvant to periodontal therapy. A wide-spectrum antibiotic, it is taken for fewer days than other formulations, improving patient compliance (14). Currently, due to the increasing global concern about bacterial resistance, compliance is a paramount aspect of daily dental practice.

Although FMS and OSRP have been compared under different conditions, their specific effects on generalized stage III and IV periodontitis are unclear, especially when combined with azithromycin. In smokers, when antimicrobials are not present, both modalities resulted in a comparable gain of attachment over a 6-month period (15). However, Gomi et al. (16) reported greater clinical and bacterial improvements when azithromycin was used prior to FMS. They also reported increased clinical benefits of QSRP when used in conjunction with azithromycin for the treatment of moderate-severe periodontitis. Fonseca et al. (17) conducted a clinical trial with 85 mild to moderate periodontitis patients randomly divided into six different treatment groups. The adjuvant use of azithromycin did not provide any significant benefit, independently of the treatment protocol while the adjuvant use of $\mathrm{CHX}$ did present a significant improvement of clinical and microbiologic parameters, especially in regard to the FMD protocol.

The primary aim of this 6-month, randomized, controlled, clinical trial was to evaluate the effectiveness of azithromycin compared to OSRP in non-surgical periodontal therapy performed through FMS for the treatment of generalized generalized stage III and IV periodontitis. A secondary objective was to evaluate whether the therapies would create improvements in regard to total bacterial load, levels of red complex bacterial species, and volume of GCF.

\section{Material and Methods}

The present randomized clinical trials study was approved by the Ethics Committee on Research of the University of Taubaté, São Paulo, Brazil (Protocol 521/10). All individuals were provided with written informed consent documents before enrolling in the study, which was composed of baseline, 3-month, and 6-month posttreatment appointments. The present study was registered at clinicaltrials.gov (NCT02215460).

\section{Study Population}

The study population was composed of generalized stage III and IV periodontitis patients of both sexes who were 35 years or older, had at least 20 natural teeth, were in good general health, and were registered in the periodontal screening program of the University of Taubaté Dental School from August, 2014 to August, 2015 (Fig. 1).

Based on the new classification and diagnosis of periodontal diseases proposed by the American Academy of Periodontology and European Federation of Periodontology (18), the study included subjects with generalized periodontitis (stage III or IV, with over 30\% of affected sites). In relation severity and complexity of management, the stage III (severe periodontitis), the individual should present at least: interdental clinical attachment loss (CAL) $\geq 5 \mathrm{~mm}$, radiographic bone loss extending to mild-third of root; and tooth loss due to periodontitis. The stage IV (advanced periodontitis) is characterized by interdental CAL $\geq 5 \mathrm{~mm}$ and presence of deep periodontal lesions that extend to the apical portion of the root, and/or history of multiple tooth loss $(18,19)$.

Exclusion criteria included the following: 1) systemic diseases or other conditions that could influence the periodontal status; 2 ) history of sensitivity or suspected allergies after the use of azithromycin or chlorhexidine; 3) use of orthodontic devices, extended prosthetic fixed devices, removable partial dentures, or overhanging restorations; 4) pregnant or breastfeeding; 5) need for antibiotic prophylaxis; 6) antibiotics and/or antiinflammatory drug use within the 6 months preceding the study; 7) regular use of chemotherapeutic antiplaque/ antigingivitis products; 8 ) periodontal treatment performed within 6 months of the study; 9) furcation lesions; and 10) unwillingness to return for follow-up.

Periodontal probing depth (PD) reduction and gain in CAL were considered to calculate the sample size. Based on a previous study (17), a minimum of 15 patients per group was determined for severe periodontitis. Allowing for up to a 20\% dropout rate during the 6 months of the follow-up, the initial sample size was defined as at least 15 patients per group.

\section{Clinical Periodontal Examinations}

Participants underwent a complete periodontal examination during the screening phase to determine their periodontal diagnosis. This was in addition to the baseline, 3-month, and 6-month follow-up examinations after the periodontal treatment. PD, CAL, PI (plaque index) (20) and GI (gingival index) (21) measurements were taken from six periodontal sites on all teeth (with the exception of the third molars) by a single-blind and calibrated examiner (JRC) using a manual periodontal probe. Seven days after 
baseline and one week prior to 6-month measurements, periodontal examinations of 10 subjects were once again conducted, showing intra-examiner reproducibility scores higher than 0.85 (Kappa Test) for PD and CAL. An intra-class correlation test showed scores higher than 0.90 .

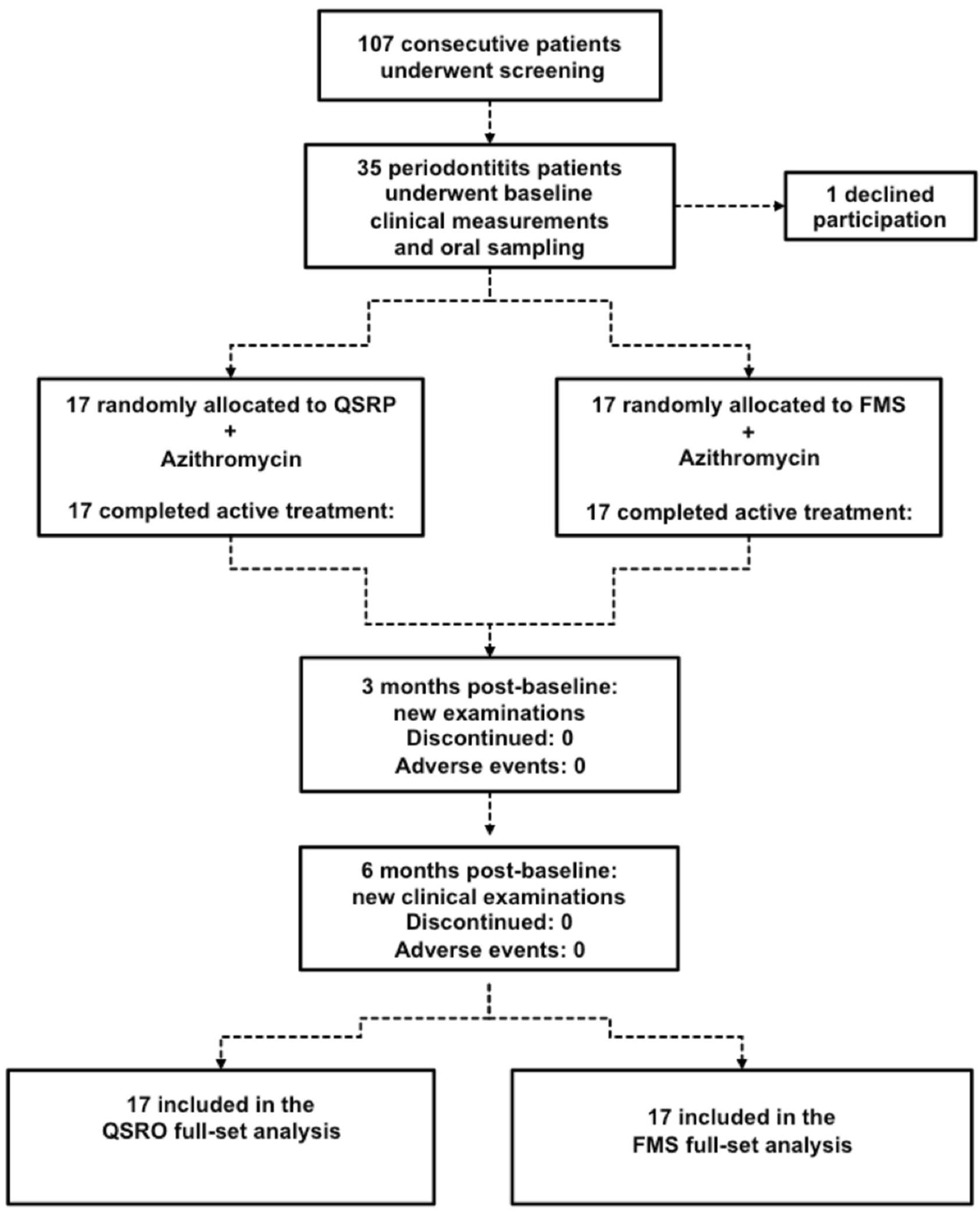

Figure 1. Study design from screening to completion of the trial. 


\section{Periodontal Treatment}

Patients were randomly allocated to one of the two treatment groups through a closed envelope system. Opaque envelopes containing the identifications of the treatment groups were sealed, mixed, and then sequentially numbered. Each new participant took a single envelope which was then opened by a blind researcher (SCC) for the intervention group. Patients attended clinical appointments on selected days according to their type of scaling.

Based on their group, participants received either conventional OSRP in four weekly sessions or FMS within $24 \mathrm{~h}$. More specifically, the OSRP group received dental scaling procedures in quadrants (30 min per quadrant) in weekly intervals between sessions. Patients received azithromycin $(500 \mathrm{mg}$ ) once a day for 3 consecutive days beginning on the first day of QSRP procedures. The FMS group received dental scaling procedures in two sessions within $24 \mathrm{~h}$ (60 min each session) for two consecutive days. This included taking azithromycin ( $500 \mathrm{mg} /$ day) once a day for 3 consecutive days beginning on the first day of scaling procedures. As a variation of the original protocol, no $\mathrm{CHX}$ irrigation or rinsing was prescribed (8). Scaling procedures $\dot{*}$ of both protocols were conducted by two experienced, trained periodontists using manual Gracey and McCall curettes and Hirschfield files.

\section{Microbial Analyses}

Subgingival samples were collected by our group (22), as described previously. More specifically, subgingival samples were collected from the mesio-buccal aspect of the five teeth showing the greatest evidence of periodontal disease using sterile paper points (\# 30) inserted into the depth of the pocket (after the removal of supragingival plaque using sterile curettes). Sixty seconds after their insertion into the pocket, paper points were then inserted into a microtube and placed on ice. The bacterial cells in the microtubes were dispersed using a vortex mixer at maximum speed for one minute with the resulting bacterial suspension saved in a freezer at $-80{ }^{\circ} \mathrm{C}$ for laboratorial processing.

Genomic DNA (gDNA) was extracted and purified from the pellet using PureLink ${ }^{\circledR}$ Genomic DNA Mini Kit (Life Technologies, Carlsbad, CA, USA) according to the manufacturer's specifications.

The quantification of the total number of bacterial cells, Porphyromonas gingivalis, Tannerella forsythia, and Treponema denticola, was carried out by a quantitative realtime polymerase chain reaction (qPCR) using TaqMan assay (TaqMan ${ }^{\circledR}$ Universal PCR Master Mix II, Life Technologies) with a specific set of primers/probes: Porphyromonas gingivalis (forward: ACC TTA CCC GGG ATT GAA ATG; reverse: CAA CCA TGC AGC ACC TAC ATA GAA; probe: VICATG ACT GAT GGT GAA AAC CGT CT CCC TTC TAMRA);
Tannerella forsythia (forward: AGC GAT GGT AGC AAT ACC TGT C; reverse: TC GCC GGG TTA TCC CTC; probe: 6FAMCAC GGG TGA GTA ACGTAMRA); Treponema denticola (forward: CCG AAT GTG CTC ATT TAC ATA AAG GT; reverse: GAT ACC CAT CGT TGC CT GGT; probe: 6FAMATG GGC CCG CGT CCC ATT AGC TAMRA) in an ABI 7500 Fast Real Time (PCR System ${ }^{\circledR}$, Life Technologies) in $20 \mu \mathrm{L}$ reactions following the manufacturer's instructions. The qPCR conditions were: $50{ }^{\circ} \mathrm{C}$ for $2 \mathrm{~min}, 95{ }^{\circ} \mathrm{C}$ for $10 \mathrm{~min}, 40$ cycles of $95^{\circ} \mathrm{C}$ for $15 \mathrm{~s}$, and $60^{\circ} \mathrm{C}$ for $1 \mathrm{~min}$.

The absolute quantification of the target organism was determined by the plotting of the cycle threshold (Ct) value obtained from each clinical sample against a standard curve generated with a known concentration of gDNA of reference bacterial strains in 10-fold serial dilutions. Negative control (i.e., purified PCR-grade water instead of the DNA template) was included in all PCR reactions.

\section{Gingival Crevicular Fluid}

GCF was collected from the same sites that were microbiologically sampled. After an interval of $90 \mathrm{~s}$ following subgingival biofilm collection, the teeth were washed, isolated with sterile cotton rolls, and gently dried. GCF was collected by placing filter paper strips into the gingival pocket until there was a slight resistance and then left there for $15 \mathrm{~s}$. After filter paper removal, the volume of the sample was immediately measured using a calibrated electronic gingival fluid measuring device (Oraflow, Plainview, NY, USA).

\section{Statistical Analysis}

The primary outcome was PD and CAL improvements. Normality and range of variance were evaluated by Kolmogorov-Smirnov and Levene tests. Then, to evaluate the influence of group (FMS or OSRP) and time (baseline, 3-month, and 6-month) on the variables, a repeatedmeasures analysis of variance (ANOVA) was performed followed by a least significant difference (LSD) multiple comparisons test based on a statistically significant effect. GCF at each time-point was evaluated by a Kruskal-Wallis test, while its mean volume within each group was analyzed by a Friedman test. Microbiological data were analyzed using a paired Student's t-test. All tests employed a significance level of $5 \%(p<0.05)$.

\section{Results}

The study's population was comprised of 34 individuals (56.65\% female, $43.33 \%$ male (Table 1). Table 2 shows the comparisons in relation to periodontal clinical parameters at baseline, 3 months and 6 months. At the baseline, groups were homogeneous in relation to all periodontal clinical parameters. In both groups, a significant reduction was 
observed in the mean values of periodontal parameters from the baseline to 6 months after treatment, demonstrating the effectiveness of both treatment protocols.

Figure 2 shows the improvements over time in the percentage of periodontal sites according to PD and CAL values. Furthermore, FMS and OSRP provided statistically significant reductions in the percentage of periodontal sites, showing $P D \geq 4 \mathrm{~mm}, P D \geq 6 \mathrm{~mm}, C A L \geq 3 \mathrm{~mm}$, and $C A L \geq 4$ $\mathrm{mm}$ with no differences between groups.

It was observed that in the FMS group, there were reductions in both total bacteria load and red complex bacterial species levels from the baseline to 6 months after therapy. Bacterial levels did not change during the last three months. A similar profile was verified for the QSRP group (intra-group analysis). In addition, it was observed that FMS presented greater reductions ( $p<0.05$, Student's t-test) in total bacterial load (mean reduction of $4,788,240.04 \pm 8,967,457.81)$ and red complex bacterial species (mean reduction of $165,107.73 \pm 410,449.29$ ) when compared to QSRP (total bacterial load mean reduction of $142,143.96 \pm 212,333.65$ and red complex mean reduction of $147,443.71 \pm 544,738.81$ ). Table 3 also illustrates that the volume of GCF reduced over time in both groups was the same.

Azithromycin was tolerated well by both groups without any observed or self-reported adverse effects.

\section{Discussion}

Since the introduction of FMS therapy (8), several authors have reported conflicting data regarding the nonsurgical periodontal therapy protocol of choice and the better-associated adjuvant. While some studies have revealed better clinical and microbiological results for the FMS protocol $(11,13)$, other studies have failed to demonstrate such results $(11,12,23)$.

In this context and due to its dosage scheme, it was hypothesized that the addition of azithromycin in FMS would provide greater benefits in comparison to OSRP. Besides the severity of periodontal disease in the present study population, the choice of azithromycin as an adjuvant to non-surgical periodontal therapy was based on the following characteristics: its broad spectrum of action, fast leukocyte and fibroblast absorption, slow release in soft tissues, and reduced number of intake days which contributes to patient compliance (14). Moreover, the substitution of azithromycin for chlorhexidine was based on the expected side effects that usually follow the extensive use of $\mathrm{CHX}$, as proposed by Quirynen et al. (8). These side effects include but are not limited to: an increase in the staining of teeth and other oral surfaces, an increase in calculus formation, and an alteration in taste perception (24). In fact, a previous study conducted by our group compared chlorhexidine and azithromycin

Table 1. Distribution of allocated population (FMS and QSRP) according to age, sex and level of education

\begin{tabular}{lccc}
\hline Group & Age & Sex & Level of education \\
\hline FMS & $47.7 \pm 8.2$ & Females $(\mathrm{n}=10)$ Males $(\mathrm{n}=7)$ & $<8$ years $\rightarrow 17.7 \%$ from 8 to 12 years $\rightarrow 58.8 \%>12$ years $\rightarrow 23.5 \%$ \\
QSRP & $45.2 \pm 8.1$ & Females $(\mathrm{n}=9)$ Male $(\mathrm{n}=8)$ & $<8$ years $\rightarrow 29.4 \%$ From 8 to 12 years $\rightarrow 58.8 \%>12$ years $\rightarrow 11.8 \%$ \\
\hline
\end{tabular}

FMS: full-mouth scaling and root planning with azithromycin; QSRP: quadrant scaling and root planning with azithromycin. Values shown in table are SD (standard deviation)

Table 2. Comparative analysis of clinical periodontal parameters overtime and between treatment groups

\begin{tabular}{|c|c|c|c|c|c|c|}
\hline Group & Time-points & PD mean & CAL mean & GI & PI & $\begin{array}{c}\text { Comparisons } \\
\text { between groups }\end{array}$ \\
\hline & 0 & $3.3 \pm 0.6$ & $3.4 \pm 0.8$ & $52.1 \pm 20.3$ & $52.3 \pm 15.3$ & $\mathrm{p}>0.05$ \\
\hline \multirow[t]{3}{*}{ FMS } & 3 months & $2.0 \pm 0.4$ & $3.0 \pm 0.9$ & $11.1 \pm 7.3$ & $25.2 \pm 10.7$ & $\mathrm{FMS}=\mathrm{QRSP}$ \\
\hline & 6 months & $1.7 \pm 0.3$ & $2.8 \pm 0.8$ & $10.5 \pm 5.4$ & $20.1 \pm 5.7$ & - \\
\hline & 0 & $3.0 \pm 0.7$ & $3.1 \pm 1.0$ & $50.1 \pm 25.1$ & $53.0 \pm 15.8$ & - \\
\hline \multirow[t]{3}{*}{ QRSP } & 3 months & $2.2 \pm 0.5$ & $2.7 \pm 1.0$ & $18.5 \pm 13.1$ & $31.0 \pm 13.6$ & $\begin{array}{c}\mathrm{p}>0.05 \\
\text { FMS }=\text { QRSP }\end{array}$ \\
\hline & 6 months & $1.8 \pm 0.4$ & $2.6 \pm 0.9$ & $13.1 \pm 10.3$ & $24.0 \pm 9.1$ & - \\
\hline & Comparisons among examination times & $\begin{array}{c}p<0.001 \\
0>90>180\end{array}$ & $\begin{array}{c}p=0.008 \\
0>180\end{array}$ & $\begin{array}{c}\mathrm{p}<0.001 \\
0>(90=180)\end{array}$ & $\begin{array}{c}\mathrm{p}<0.001 \\
0>90>180\end{array}$ & $\begin{array}{l}- \\
-\end{array}$ \\
\hline
\end{tabular}

FMS:full-mouth scaling with azithromycin; QSRP: quadrant scaling and root planning with azithromycin. Values show in table are (standard deviation) and median (Md) PD = probing depth; $\mathrm{CAL}=$ clinical attachment level; $\mathrm{GI}$ = gingival index; $\mathrm{PI}=$ plaque index. 

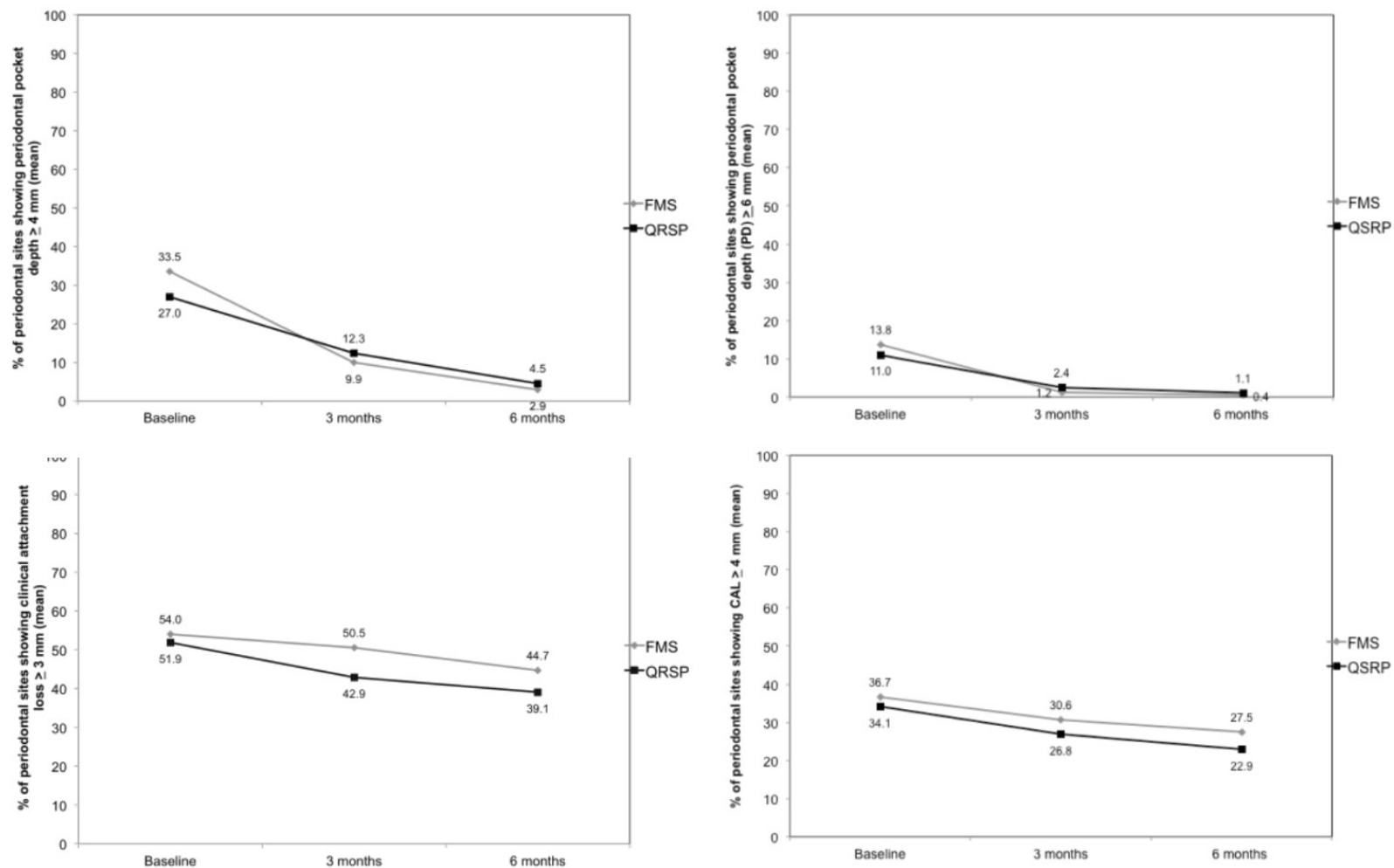

$\vec{\sigma}$ Figure 2. Percentage of periodontal sites in specific categories of PD and CAL according to treatment group and examination times.

Table 3. Intra and inter-group (FMS vs. QSRP) comparisons regarding microbiological parameters and gingival crevicular fluid

\begin{tabular}{|c|c|c|c|c|}
\hline \multirow{2}{*}{ Group } & \multicolumn{3}{|c|}{ Total bacterial load } & \multirow{2}{*}{$\begin{array}{l}\mathrm{p}^{* *} \text { (comparisons } \\
\text { among time-points) }\end{array}$} \\
\hline & Baseline & 3 months & 6 months & \\
\hline FMS & $\begin{array}{l}6.162 .042 .48 \pm \\
13,912,601.36\end{array}$ & $1,373,802.44 \pm 4,055,775.36$ & $1.587 .279 .36 \pm 4,572,285.71$ & $\begin{array}{c}\mathrm{p}<0.001 \\
0>(3 \mathrm{mo}=6 \mathrm{mo})\end{array}$ \\
\hline QSRP & $6,844,499.11 \pm 12,749,029.10$ & $6,702,355.14 \pm 11,563,904.10$ & $6.874 .243 .27 \pm 10,349,578.32$ & $\begin{array}{c}\mathrm{p}<0.001 \\
0>(3 \mathrm{mo}=6 \mathrm{mo})\end{array}$ \\
\hline $\begin{array}{l}\mathrm{p}^{*} \text { (comparisons } \\
\text { between groups) }\end{array}$ & $\begin{aligned} \mathrm{p} & =0.823 \\
\mathrm{FMS} & =\mathrm{QSRP}\end{aligned}$ & $\begin{array}{c}\mathrm{p}<0.001 \\
\mathrm{QSRP}>\mathrm{FMS}\end{array}$ & $\begin{array}{c}\mathrm{p}<0.001 \\
\mathrm{QSRP}>\mathrm{FMS}\end{array}$ & - \\
\hline \multirow{2}{*}{ Group } & \multicolumn{3}{|c|}{$\begin{array}{c}\text { Red complex bacterial species (concomitant presence of } \\
P . \text { gingivalis, T. forsythia and T. denticola) }\end{array}$} & $\mathrm{p}^{* * *}$ (comparisons \\
\hline & Baseline & 3 months & 6 months & among time-points) \\
\hline FMS & $173,810.27 \pm 420,632.51$ & $8,702.54 \pm 34,199.75$ & $7,963.92 \pm 35,481.54$ & $\begin{array}{c}p<0.001 \\
0>(3 \mathrm{mo}=6 \mathrm{mo})\end{array}$ \\
\hline QSRP & $245,299.78 \pm 894,339.00$ & $97,856.07 \pm 462,228.79$ & $98,537.11 \pm 445,894.39$ & $\begin{array}{c}\mathrm{p}<0.001 \\
0>(3 \mathrm{mo}=6 \mathrm{mo})\end{array}$ \\
\hline $\begin{array}{l}\mathrm{p}^{*} \text { (comparisons } \\
\text { between groups }\end{array}$ & $\begin{array}{c}\mathrm{p}>0.05 \\
\text { FMS }=\text { QSRP }\end{array}$ & $\begin{aligned} \mathrm{p} & <0.05 \\
\mathrm{QSRP} & >\mathrm{FMS}\end{aligned}$ & $\begin{array}{c}\mathrm{p}<0.05 \\
\mathrm{QSRP}>\mathrm{FMS}\end{array}$ & - \\
\hline \multirow{2}{*}{ Group } & \multicolumn{3}{|c|}{ Gingival crevicular fluid (GCF) } & \multirow{2}{*}{$\begin{array}{l}\mathrm{p}^{* * * *} \text { (comparisons } \\
\text { among time-points) }\end{array}$} \\
\hline & Baseline & 3 months & 6 months & \\
\hline FMS & $160.5 \pm 33.2$ & $94.6 \pm 21.1$ & $54.9 \pm 13.5$ & $\begin{array}{c}\mathrm{p}<0.001 \\
0>90>180\end{array}$ \\
\hline QSRP & $148.1 \pm 32.7$ & $88.6 \pm 31.1$ & $63.5 \pm 24.9$ & $\begin{array}{c}p<0.001 \\
0>(90=180)\end{array}$ \\
\hline $\mathrm{p}^{* * * * *}$ (comparisons & $\mathrm{p}>0.05$ & $p>0.05$ & $p>0.05$ & \\
\hline between groups & $\mathrm{FMS}=\mathrm{QSRP}$ & FMS $=$ QSRP & $\mathrm{FMS}=\mathrm{QSRP}$ & \\
\hline
\end{tabular}

Total bacterial load and red complex bacterial species values in the table refer to mean number of bacteria; *Student t test; **paired-t test. GCF values in the table refer to ; ${ }^{* * *}$ Friedman test; ${ }^{* * * *}$ Kruskal-Wallis test 
in regard to being adjuvants of FMS and QSRP. In patients with mild to moderate periodontitis, $\mathrm{CHX}$ showed more significant improvements in clinical and microbiological parameters than azithromycin, especially in regard to the FMD protocol (17).

It is also important to keep in mind that, in particular, FMS protocol aims to quickly eradicate or at least suppress all periodontopathogens not only from the periodontal pockets but from all oro-pharyngeal habitats (i.e., mucous membranes, the tongue, tonsils, saliva). As such, the re-colonization of the treated pockets by bacteria from untreated sites (i.e., cross-contamination or intraoral translocation) could indeed be delayed until better healing of the pockets is achieved. In the present study, FMS displayed a greater reduction in both total bacteria and selected species which was revealed by the lower mean levels observed in the FMS group compared to the QSRP group.

According to the parameters of $\mathrm{PD}, \mathrm{CAL}, \mathrm{GI}$, and $\mathrm{PI}$, our results illustrated that the addition of azithromycin produces similar clinical, beneficial effects in both therapies after 6 months of therapeutic procedures (Table 2). Except for $C A L$, these improvements can be observed even earlier, such as 3 months into the procedures. GCF followed these same patterns of evolution over time. Traditionally, periodontal debridement procedures are performed in quadrants or sextants in regular intervals of one or two weeks. The clinical success of this type of treatment occurs primarily because of the reduction of periodontal pathogens which are generally accompanied by an increase of beneficial bacteria and the subsequent establishment of a healthy microbiota. In systematic reviews that evaluated several antimicrobials, similar improvements were also observed when conventional and FMS therapies were compared $(11,12)$.

The microbiota of the human oral mucosa consists of a myriad of bacterial species that normally exist in commensal harmony with the host. Porphyromonas gingivalis, an etiological agent in severe forms of periodontitis, is a prominent component of the oral microbiome and a successful colonizer of the oral epithelium. Since 1998, this pathogen has been studied in combination with Tannerella forsythia and Treponema denticola. This pathogenic consortium of bacteria, called the red complex bacterial species, is strongly correlated with periodontitis. In addition, the monitoring of the red complex species is relevant in periodontal clinical research due to its relation to the progression of periodontitis (4). In the present study, red complex bacterial reductions were observed at 3 months and sustained at 6 months, contributing to a healthy periodontium after treatment was applied over time. The chronic persistence of these pathogens in the periodontium depends on their ability to evade host immunity without inhibiting the overall inflammatory response, which is actually beneficial to periodontal bacteria. Indeed, the inflammatory exudate (GCF) is a source of essential nutrients such as peptides and hemin-derived iron (25). Therefore, the GCF reduction observed in the present study could positively contribute to reduced bacteria levels over time. Specific immunological analysis can be considered a limitation of the present study that should be addressed in the future. In addition, although frequently used in randomized clinical trials, convenience samples could aid the reduction of external validity.

Overall, the hypothesis was accepted because statistically significant reductions of these bacterial parameters were observed in both groups treated with adjuvant azithromycin (Table 3). Our study has shown that in generalized stage III and IV periodontitis, FMS combined with azithromycin was more effective in modifying subgingival microbiota through a reduction in total bacteria load and red complex bacterial levels (Table 3). Azithromycin appeared to enhance the effects of FMS, since this antibiotic was detected in initially inflamed periodontal tissues 14 days after systemic administration (16). These findings could aid clinical choices regarding FMS or QSRP indications. Further studies are required to confirm whether FMS or QSRP would be the best therapeutic option for severe periodontitis in regard to red complex bacteria species.

As the FMS and OSRP therapies exhibited similar clinical results, it can be concluded that both techniques represent valid therapeutic options. However, FMS produced greater bacterial reductions at 3 months, which were also maintained at 6 months. Therefore, it is relevant to take into consideration the patient's choice, as some prefer FMS because of convenience and accessibility (i.e., two appointments instead of four, thus making it less expensive, easier to travel to, etc.). In all, in dental practice, the decision to select either the FMS or OSRP approach should involve patient preference, the capabilities of the operator, and the convenience of the treatment schedule.

In summary, FMS and OSRP in conjunction with systemic azithromycin displayed similar effectiveness and appear to both be reliable short-term therapeutic approaches for the treatment of generalized stage III and IV periodontitis. However, FMD demonstrated superiority in regard to 6-month antibacterial effects compared to QSRP.

\section{Resumo}

A efetividade da azitromicina combinada com a técnica de desinfecção total da boca (DTB) foi comparada a raspagem por quadrante (RQ) utilizando a mesma dosagem de azitromicina no tratamento de indivíduos com periodontite generalizada estágio III e IV, em um periodo de 6 meses. Trinta e quatro individuos foram submetidos aos exames no baseline, 3 e 6 meses pós-tratamento. A população estudada foi alocada aleatoriamente 
no grupo DTB ou R0 associado a três dias consecutivos de azitromicina (500 mg/dia). Profundidade de sondagem (PS), nível clínico de inserção (NIC), indice gengival (IG) e o indice de placa (IP) foram monitorados, além da quantificação da carga bacteriana total e das espécies bacterianas do complexo vermelho (Porphyromonas gingivalis, Tannerella forsythia e Treponema denticola), em amostras subgengivais, a partir da reação em cadeia da polimerase em tempo real. 0 volume de fluido crevicular gengival (FCG) também foi monitorado ao longo do tempo. Os resultados primários foram melhorias de PS e NIC. Os dados foram analisados estatisticamente por Análise de variância (ANOVA), comparações múltiplas de diferença menor (LSD), Kruskal-Wallis, Friedman e teste t de Student emparelhado $(p<0,05)$. DTB e RO forneceram melhorias em PS, NIC, IG, IP e FCG semelhantes. Após o tratamento, o grupo DTB apresentou valores médios mais baixos da carga bacteriana total e de espécies bacterianas do complexo vermelho em comparação com o grupo RO. DTB e RQ associado a azitromicina sistêmica mostraram ser similarmente uma abordagem terapêutica de curto prazo, eficaz e confiável para o tratamento de periodontite generalizada estágio III e IV. No entanto, DTB demonstrou superioridade sobre os efeitos antibacterianos aos 6 meses em comparação com RQ.

\section{Acknowledgements}

The authors declare that they have no conflict of interest related to the present study. This study was financially supported by Brazilian research funding institutions. Specifically, by the National Council of Scientific and Technological Development (CNPq) grant \#307152/2012-0, CNPq undergraduate scholarship \#2015/02890-9 and São Paulo research foundation (Fapesp) graduate scholarship \#2015/02995-5.

\section{References}

1. Yashima A, Gomi K, Maeda N, Arai T. One-stage full-mouth versus partial-mouth scaling and root planing during the effective half-life of systemically administered azithromycin. J Periodontol 2009;80:14061413.

2. Sahl EF, Henkin JM, Angelov N. Recovery of putative periodontal pathogens from curette sampling at different depths of periodontal lesions: an in vivo cross-sectional clinical study. J Int Acad Periodontol 2014;16:78-85.

3. Shaikh HFM, Patil SH, Pangam TS, Rathod KV. Polymicrobial synergy and dysbiosis: An overview. J Indian Soc Periodontol 2018;22:101-106.

4. Socransky SS, Haffajee AD, Cugini MA, Smith C, Kent RL Jr. Microbial complexes in subgingival plaque. J Clin Periodontol 1998;25:134-144.

5. Van der Velden U. What exactly distinguishes aggressive from chronic periodontitis: is it mainly a difference in the degree of bacterial invasiveness? Periodontol 2000 2017;75:24-44.

6. Eick $S$, Nydegger J, Bürgin W, Salvi GE, Sculean A, Ramseier C. Microbiological analysis and the outcomes of periodontal treatment with or without adjunctive systemic antibiotics-a retrospective study. 2018;22:3031-3041.

7. Badersten $A$, Nilveus R, Egelberg J. Effect of nonsurgical periodontal therapy (VIII). Probing attachment changes related to clinical characteristics. J Clin Periodontol 1987;14:425-432.

8. Quirynen M, Bollen CM, Vandekerckhove BN, Dekeyser C, Papaioannou W, Eyssen H. Full-vs. partial-mouth disinfection in the treatment of periodontal infections: short-term clinical and microbiological observations. J Dent Res 1995;74:1459-1467.

9. Teughels W, Dekeyser C, van Essche M, Quirynen M. One-stage full- mouth disinfection: Fiction or reality? Periodontol 2000 2009:50:3951.

10. Graziani $F_{1}$ Karapetsa D, Alonso $B$, Herrera D. Nonsurgical and surgical treatment of periodontitis: how many options for one disease? Periodontol 2000 2017;75:152-188.

11. Lang NP, Tan WC, Krähenmann MA, Zwahlen M. A systematic review of the effects of full-mouth debridement with and without antiseptics in patients with chronic periodontitis. J Clin Periodontol 2008;35:8-21.

12. Eberhard J, Jepsen S, Jervøe-Storm PM, Needleman I, Worthington HV. Full-mouth treatment modalities (within $24 \mathrm{~h}$ ) for chronic periodontitis in adults. Cochrane Database Syst Rev 2015;4:CD004622.

13. Fang $\mathrm{H}$, Han $\mathrm{M}, \mathrm{Li} \mathrm{QL}, \mathrm{Cao} \mathrm{CY}, \mathrm{Xia} \mathrm{R}, \mathrm{Zhang} \mathrm{ZH}$. Comparison of fullmouth disinfection and quadrant-wise scaling in the treatment of adult chronic periodontitis: a systematic review and meta-analysis. $J$ Periodontol Res 2016;51:417-430.

14. Sampaio E, Rocha M, Figueiredo LC, Faveri M, Duarte PM, Gomes Lira $E A$, et al. Clinical and microbiological effects of azithromycin in the treatment of generalized chronic periodontitis: a randomized placebocontrolled clinical trial. J Clin Periodontol 2011;38:838-846.

15. Meulman T, Giorgetti AP, Gimenes J, Casarin RC, Peruzzo DC, Nociti $\mathrm{FH}$ Jr. One stage full-mouth ultrasonic debriment in the treatment of severe chronic periodontits in smokers: a preliminary blind and randomized clinical trial. J Int Acad Periodontol 2013;15:83-90.

16. Gomi K, Yashima A, Nagano T, Kanazashi M, Maeda N, Arai T. Effects of full-mouth scaling and root planning in conjunction with systemically administered azithromycin. J Periodontol 2007;78:422-429.

17. Fonseca DC, Cortelli JR, Cortelli SC, Miranda Cota LO, Machado Costa LC, Moreira Castro MV, et al. Clinical and microbiologic evaluation of scaling and root planning per quadrant and one-stage full-mouth disinfection associated with azithromycin or chlorhexidine: a clinical randomized controlled trial. J Periodontol 2015;86:1340-1351.

18. G Caton J, Armitage G, Berglundh T, Chapple ILC, Jepsen S, S Kornman $K$, et al. A new classification scheme for periodontal and peri-implant diseases and conditions - Introduction and key changes from the 1999 classification. J Periodontol 2018;89:S1-S8.

19. Tonetti MS, Greenwell H, Kornman KS. Staging and grading of periodontitis: Framework and proposal of a new classification and case definition. J Periodontol 2018;89:S159-S172.

20. Silness J, Loe H. Periodontal disease in pregnancy. II. Correlation between oral hygiene and periodontal condition. Acta Odontol Scand 1964:22:121-135.

21. Loe $H$, Silness J. Periodontal disease in pregnancy I. Prevalence and severity. Acta Odontol Scand 1963;21:533-551.

22. Cortelli SC, Costa FO, Rodrigues E, Cota LO, Cortelli JR. Periodontal therapy effects on nitrite related to oral bacteria: a 6-month randomized clinical trial. J Periodontol 2015;86:984-994.

23. Jervøe-Storm PM, Semaan $E_{1}$ AlAhdab $H$, Engel S, Fimmers $R$, Jepsen $S$. Clinical outcomes of quadrant root planing versus full-mouth root planing. J Clin Periodontol 2006;33:209-215.

24. Van Strydonck DA, Slot DE, Van der Velden U, Van der Weijden F. Effect of a chlorhexidine mouthrinse on plaque gingival inflammation and staining in gingivitis patients: a systematic review. J Clin Periodontol 2012;39:1042-1055.

25. Hajishengallis G. Immune evasion strategies of Porphyromonas gingivalis. J Oral Biosci 2011;53:233-240.

Received January 8, 2019 Accepted May 22, 2019 